\title{
Is there a role for fibronectin upon true histiocytic lymphoma progression?
}

\author{
MARCO AUGUSTO STIMAMIGLIO ${ }^{1,3}$, SUSE DAYSE SILVA-BARBOSA ${ }^{1}$, \\ MARIA APARECIDA CUSTÓDIO DOMINGUES ${ }^{2}$, ANDRÉA GONÇALVES TRENTIN ${ }^{3}$, \\ MARCIO ALVAREZ-SILVA ${ }^{3 *}$ and WILSON SAVINO ${ }^{*}$
}

\begin{abstract}
${ }^{1}$ Laboratory on Thymus Research, Oswaldo Cruz Institute, Oswaldo Cruz Foundation, Rio de Janeiro, Ave. Brasil 4365, Manguinhos, Rio de Janeiro 21045-900; ${ }^{2}$ Laboratory of Hemopathology, Hematology and Hemotherapy Center of Santa Catarina, Ave. Othon Gama D,Eça 756, Florianópolis 88015-240; ${ }^{3}$ Department of Cell Biology, Embryology and Genetics, Biological Sciences Center, Federal University of Santa Catarina, Trindade, Florianópolis 88040-900, Brazil
\end{abstract}

Received February 26, 2008; Accepted April 22, 2008

DOI: 10.3892/ijo_00000035

\begin{abstract}
Cell interaction with extracellular matrix is a crucial event for various biological processes, including tumor progression. Although not exclusively, these interactions are frequently mediated by bidirectional signaling receptors known as integrins. Using a human histiocytic lymphomaderived cell line (U-937), we evaluated the effects of ECM proteins and their integrin-type receptors in the regulation of cell attachment, proliferation, migration and survival. Fibronectin induces higher cell attachment in vitro when compared to laminin. Fibronectin also promotes a decrease in cell migration but do not modulate cell proliferation and death. Pre-incubation of U-937 cells with VLA-5 antagonistic peptides inhibited attachment of the cells to fibronectincoated substrates. In a second vein, we observed that lymph node specimens obtained from diagnosed patient for true histiocytic lymphoma had greater deposition of fibronectin (but not laminin) around malignant clones. These results suggest that fibronectins play a relevant role in the establishment and progression of true histiocytic lymphoma cells.
\end{abstract}

Correspondence to: Dr Wilson Savino, Laboratory on Thymus Research, Oswaldo Cruz Institute, Oswaldo Cruz Foundation, Rio de Janeiro, Ave. Brasil 4365, Manguinhos, Rio de Janeiro 21045-900, Brazil

E-mail: savino@fiocruz.br; w_savino@hotmail.com

Dr Marcio Alvarez-Silva, Department of Cell Biology, Embryology and Genetics, Biological Sciences Center, Federal University of Santa Catarina, Trindade, Florianópolis 88040-900, Brazil

E-mail: malvarez@ccb.ufsc.br

*Both senior authors contributed equally

Key words: histiocytic lymphoma, U-937, integrins, extracellular matrix, fibronectin, lymph nodes

\section{Introduction}

Cell interaction with extracellular matrix (ECM) is a crucial event for various biological processes, including cell proliferation, differentiation, migration and death, as well as tumor growth and metastasis (1). The complex process of tumor cell growth and metastasis consists of a series of steps, in which tumor cells progress from cell-cell interactions to cell-ECM interactions mainly involving cell surface adhesion molecules (2), including, among others, integrins, selectins, members of the immunoglobulin gene superfamily, cadherins and CD44 $(3,4)$.

Integrins are a diverse family of glycoproteins that form heterodimeric receptors composed of non-covalently associated $\alpha$ and $\beta$ subunits (5). These molecules are bidirectional signaling receptors which convey information both into and out of the cell (6). Several integrins of the $\beta_{1}$ and $\beta_{2}$ family have been identified in hematopoietic cells. Among $\beta_{1}$-integrins, a particular role has been attributed to $\alpha 4 \beta 1$ (CD49d/CD29) and $\alpha 5 \beta 1$ (CD49e/CD29) for the adhesion of hematopoietic cells to fibronectin $(\mathrm{FN})(7,8)$. The FN cell-binding domains recognized by these integrins are the alternative spliced segment III CS (CS1) (9), and the Arg-Gly-Asp (RGD) sequence (10), respectively. Fibronectin receptors play a critical role in the attachment of hematopoietic progenitors to bone marrow (2). Additionally, these interactions can result in signal transduction that can alter proliferation and apoptosis in leukocytes (7-11).

It has been shown that in leukemia, the aberrant expression of integrins is related to infiltration in bone marrow and lymph nodes. In chronic myeloid leukemia, abnormal trafficking of malignant progenitors may be related to impaired $\alpha 4 \beta 1$ and $\alpha 5 \beta 1$ integrin-mediated adhesion to stromal cells and FN, as well as abnormal mobility onto FN substrates (12).

In the context of integrin-ECM interactions, invasive cells can exhibit selective targeting to specific locations in the host. For the true histiocytic lymphoma (THL), lymph nodes, gastrointestinal tract, skin, and soft tissues are common sites of infiltration (13). THL is a rare aggressive non-Hodgkin's lymphoma $(<0.5 \%$ of NHLs) with a very poor outcome. It is 
composed of neoplastic cells with variable morphology, with immunophenotypic evidence of histiocytic differentiation $(14,15)$. This tumor frequently has an aggressive behavior and is preferentially localized, but may occur as a disseminated disease $(16,17)$. Clinical features include weight loss, fever, lymphadenopathy and splenomegaly. The gastrointestinal tract is the most frequent extranodal localization. Infiltration of neoplastic cells is observed in central nervous system, bone, skin, lung, liver, kidney, bone marrow and soft tissues $(16,18)$. In lymph nodes, neoplastic cells tend to surround the sinuses, where they can be immunohistochemically revealed with one or more histiocytic markers: CD68, lysozyme and $\alpha-1$ anti-trypsin (15).

We investigated herein the role of fibronectin in the behavior of the U937 THL cell line, and correlated the degree of fibronectin deposition in lymph nodes from a THL patient.

\section{Materials and methods}

Reagents. RPMI-1640 culture medium, bovine serum albumin (BSA), penicillin, streptomycin, L-glutamine, propidium iodide solution, human plasma fibronectin and EHS murine sarcoma derived laminin were purchased from Sigma (Saint Louis, MO, USA), whereas fetal calf serum (FCS), EDTA and the CellTrace' CFSE cell proliferation kit were from Invitrogen (Carlsbad, CA, USA). The antibodies anti-CD49d-PE (anti-VLA-4; clone 9F10), anti-CD49e-PE (anti-VLA-5; clone IIA1), anti-CD49f-PE (anti-VLA-6; clone GoH3), anti-CD29-PE-Cy5 (clone MAR4), as well as the controls anti-mouse $\mathrm{IgG}_{1}-\mathrm{PE}$ (clone MOPC-21), anti-mouse $\mathrm{IgG}_{1}$-PE-Cy5 (clone MOPC-31C) and anti-rat $\mathrm{IgG}_{2 \mathrm{a}} \mathrm{-PE}$ (clone R35-95) were purchased from Becton-Dickinson/ Pharmingen (San Diego, CA, USA) whereas polyclonal rabbit anti-human laminin (code Z0097) and anti-human fibronectin (code A0245), immune sera, LSAB $^{+\mathrm{TM}}$ kit and liquid diaminobenzidine (DAB) were from Dako (Carpinteria, CA, USA). The apoptosis detection kit was from (R\&D Systems, Minneapolis, MN, USA) and the peptides GRGDSP (RGD peptide), EILDVPST (CS-1 peptide) and GRGESP (control RGE peptide) were synthesized by Invitrogen (EvoQuest ${ }^{\mathrm{TM}}$ Laboratory Services, Carlsbad, CA, USA).

Cell culture. The human histiocytic lymphoma cell line U-937 (19) was obtained from the Rio de Janeiro Cell Bank (Federal University of Rio de Janeiro). Cells were grown under standard cell culture conditions, in RPMI-1640 medium containing $2 \times 10^{-3} \mathrm{M}$ L-glutamine, $100 \mathrm{UI} / 1$ penicillin/streptomycin, and supplemented with $10 \%(\mathrm{v} / \mathrm{v})$ heat-inactivated fetal calf serum, in $25 \mathrm{~cm}^{2}$ flasks (Costar, Cambridge, MA, USA). Growth and morphology were checked twice a week and the cells used for experimentation were at the third culture passage.

Flow cytometric analysis. Detection of ECM receptors on U-937 cell membrane was carried out by cytofluorometry as described elsewhere (20). Cells ( $10^{6}$ viable cells per well) were plated in 96-well microplates (Nalge Nunc International, Naperville, USA). Cell suspensions were first incubated with purified mouse IgG (used for blocking Fc receptors), and subjected to anti-CD49d-PE, anti-CD49e-PE, anti-CD49f-PE or anti-CD29-PE-Cy5 mAb, or to the corresponding IgG- matched negative controls. Cells were ultimately analyzed using a FACScalibur apparatus (Becton Dickinson, San Jose, CA, USA). A cell gate excluding cell debris and non-viable cells was determined using forward and side scatter parameters, and was confirmed in some experiments with the use of propidium iodide staining and immediate analysis of unfixed cells. Analyses were done after recording at least 10,000 events for each sample.

Cell adhesion assay. To assess the adhesive capacity of U-937 cells on ECM substrata, cells were washed, and submitted to a cell adhesion assay on plates (24-well plates, Nalge Nunc International) pre-coated with $10 \mu \mathrm{g} / \mathrm{ml} \mathrm{FN}$, laminin or BSA overnight at $4^{\circ} \mathrm{C}$, as previously described (21). The wells were washed three times with adhesion buffer $(0.5 \%$ BSA in RPMI-1640 medium) and blocked with RPMI-1640 containing $1 \% \mathrm{BSA}$ for $1 \mathrm{~h}$ at $37^{\circ} \mathrm{C}$. Cells were them added to the wells ( $2 \times 10^{5}$ cells per well in $500 \mu 1$ adhesion buffer) for $1 \mathrm{~h}$ at $37^{\circ} \mathrm{C}$, followed by $30 \mathrm{~min}$ of incubation under shaking $(60 \mathrm{rpm})$. After further washing to remove nonadherent cells, adherent cells were detached with ice-cold RPMI-1640 containing $5 \mathrm{mM}$ EDTA and counted in a hemocytometer. When testing for peptide blocking activity, U-937 cells were pre-incubated in the presence of soluble peptides (RGD, CS-1, RGD and CS-1 or RGE; $500 \mu \mathrm{g} / \mathrm{ml}$ ) for $1 \mathrm{~h}$ in ice bath, before adhesion to $\mathrm{FN}$.

Cell proliferation assay. Labeling of U-937 cells with carboxyfluorescein diacetate succinimidyl ester (CFSE) was performed as described previously (22) with minor modifications. In brief, U937 cells were washed twice and resuspended in prewarmed $\mathrm{PBS} / 0.1 \% \mathrm{BSA}$ at a final concentration of $1 \times 10^{6}$ cells $/ \mathrm{ml}$, then incubated in $1 \mu \mathrm{M}$ CFSE (Molecular Probes, USA) at $37^{\circ} \mathrm{C}$ for $15 \mathrm{~min}$. Cells were washed again before addition to cell proliferation assays on 24-well plates pre-coated with $10 \mu \mathrm{g} / \mathrm{ml} \mathrm{BSA}$ or FN. Two hundred thousand cells were added to each well (in $1 \mathrm{ml}$ RPMI-1640) for 1, 24, 48 and $72 \mathrm{~h}$ at $37^{\circ} \mathrm{C}$. CFSE-labeled cells were then harvested from individual wells, washed in ice-cold PBS $/ 0,1 \%$ BSA, resuspended and fixed in $200 \mu 11 \%$ paraformaldehyde. Growing cells were ultimately analyzed using a FACScalibur apparatus (Becton Dickinson).

Cell migration assay. Migration experiments were performed using Transwell plates (6.5 mm diameter and $8 \mu \mathrm{m}$ pore size; Corning Costar, Cambridge, MA, USA), as currently used in our Laboratory to ascertain fibronectin-driven $\mathrm{T}$ cell migration (23). Both surfaces of the polycarbonate membrane were coated with $10 \mu \mathrm{g} / \mathrm{ml}$ of FN, laminin or BSA for $1 \mathrm{~h}$ at $37^{\circ} \mathrm{C}$, followed by $1 \mathrm{~h}$ blocking with $1 \%$ BSA. Cells $\left(5 \times 10^{5}\right)$ were then added to the upper chamber in $100 \mu 10.5 \%$ BSA/RPMI-1640, and $600 \mu 10.5 \%$ BSA/RPMI-1640 were added to the lower chamber. After 4-h incubation at $37^{\circ} \mathrm{C}$ in $5 \% \mathrm{CO}_{2}$-containing atmosphere, cells that migrated into lower chambers were removed and counted in a hemocytometer.

Cell survival assay. An apoptosis detection kit (R\&D Systems) was used to quantitatively determine U-937 cells undergoing apoptosis by virtue of their ability to bind annexin $\mathrm{V}$ and exclude propidium iodide (24). For the assay, cells $\left(2 \times 10^{5}\right.$ cells 


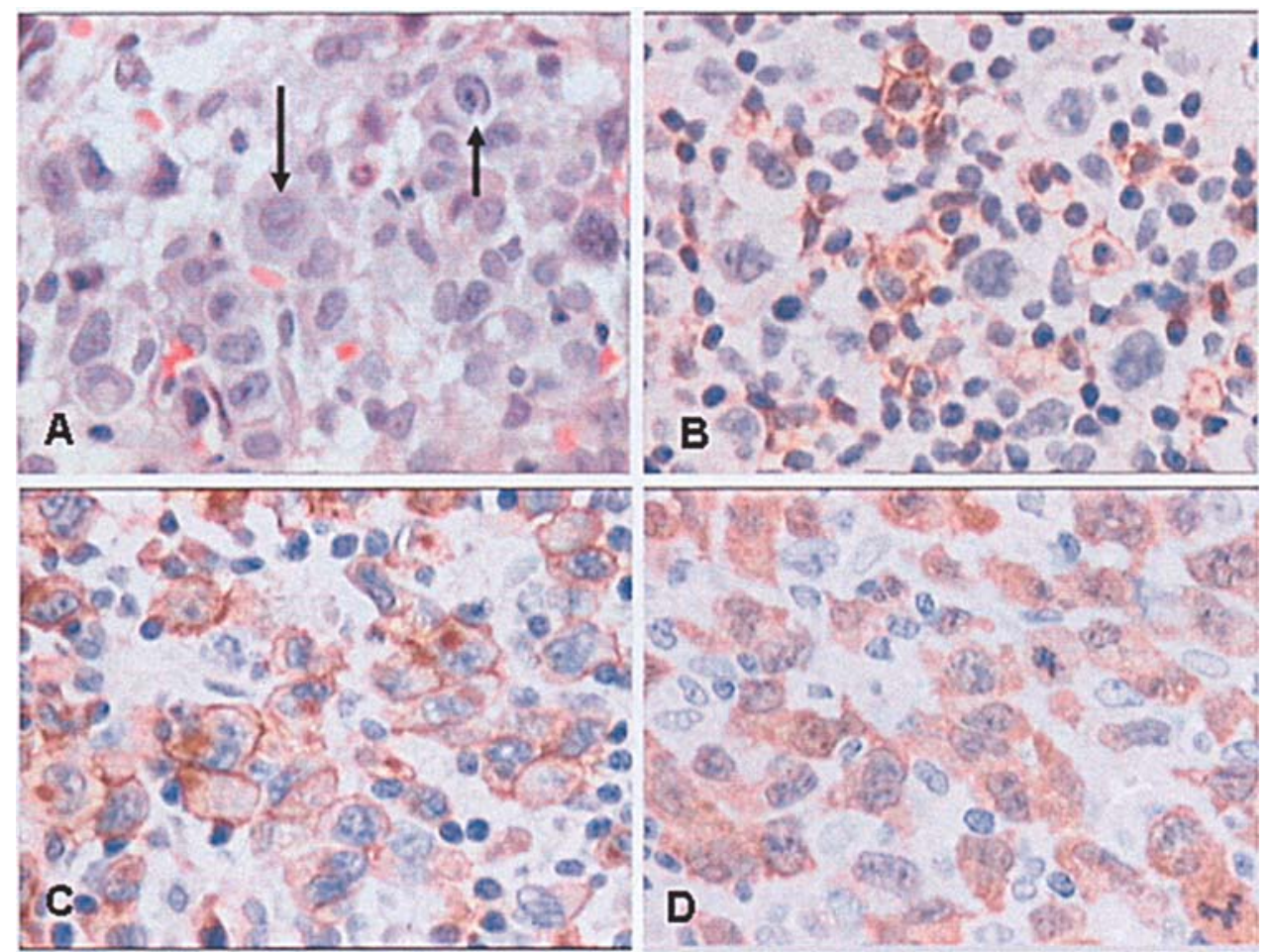

Figure 1. Histological and immunohistochemical features of lymph node from a patient diagnosed as bearing a true histiocytic lymphoma. A, hematoxylineosin staining, where malignant cells containing larger nuclei can be easily distinguished (arrow). Immunoperoxidase staining revealed that these cells are positive for CD15, CD45 and Lysozime (B, C and D, respectively). Original magnification x400.

per well in $1 \mathrm{ml}$ RPMI-1640) were cultured for 0, 24, 48 and $72 \mathrm{~h}$ at $37^{\circ} \mathrm{C}$ on plates (24-well plates, Nalge Nunc International), pre-coated with $10 \mu \mathrm{g} / \mathrm{ml} \mathrm{FN}$ or BSA and blocked with $\mathrm{PBS} / 1 \%$ BSA. Cells were then harvested from individual wells, washed once and resuspended in $100 \mu 1$ of binding buffer (100 mM HEPES, pH 7.4, containing 1.5 M NaCl, $50 \mathrm{mM} \mathrm{KCl}, 10 \mathrm{mM} \mathrm{MgCl}_{2}$, and $18 \mathrm{mM} \mathrm{CaCl}_{2}$ ) containing Annexin $\mathrm{V}^{\mathrm{FITC}}$ and $0.5 \mu \mathrm{g}$ of propidium iodide for $15 \mathrm{~min}$ at room temperature in the dark. Binding buffer was then added to the mixture, and flow cytometry was performed using a FACScalibur apparatus. The percentage of total cells that did not bind propidium iodide or Annexin V-FITC (viable cells), cells that bound Annexin V ${ }^{\text {FITC }}$ alone (early apoptosis), or cells that bound both propidium iodide and Annexin V-FITC (late apoptosis or necrosis) was determined, and the results are presented in the form of a density plot.

Lymph node samples. Representative cases of normal and neoplastic lymph nodes were selected from the Hemopathology Laboratory, Santa Catarina Center of Hematology and Hemotherapy (Santa Catarina, Brazil). This study was conducted in accordance with an approved protocol by the institutional review board and the studies were performed in accordance with the Helsinki Declaration of 1975. Cervical lymph node biopsy was performed in a 43-year old male patient, whose clinical examination revealed a bilateral cervical mass, axilar and mediastinal lymphadenomegaly and fever, with no signs of infection. The biopsy showed diffuse altered lymph node architecture with large atypical cells with pleomorphic nuclei, coarse chromatin with one or more nucleoli, and basophilic vacuolated cytoplasm. Flow cytometry and immunohisto-

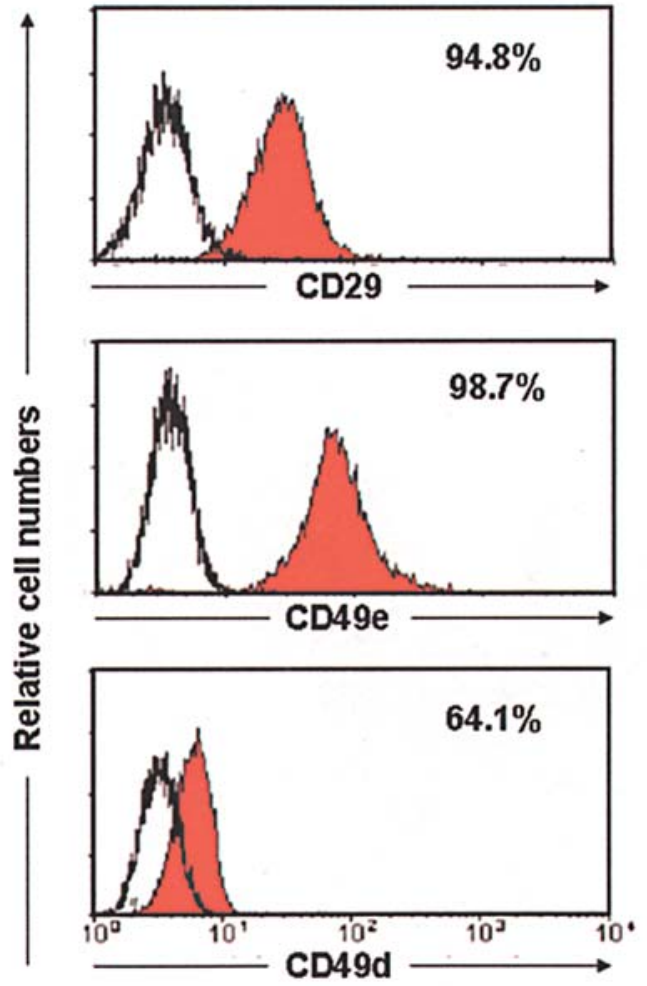

Figure 2. Differential expression of VLA-4 and VLA-5 fibronectin receptors in early cultures of true histiocytic lymphoma U-937 cells. Flow cytometric histograms show that CD29 (the $\beta_{1}$ integrin chain) is highly expressed, and the same is seen as regards the expression of CD49e (the $\alpha 5$ integrin chain that forms the FN receptor VLA-5, the integrin $\alpha 531$ or CD49e/CD29). Differently, only $60 \%$ of the cells express (at rather low density) CD49d (that forms the FN receptor VLA-4, the integrin $\alpha 431$ or CD49d/CD29). 
chemistry studies showed cells positive for CD45, CD68, $\mathrm{CD} 15$ and lysozyme, and negative for chloracetatesterase and $\mathrm{T}$ or B lymphocyte markers (see Fig. 1 for immunohistochemistry). A diagnosis of a malignant neoplasm with morphological and immunophenotypic features of true histiocytic lymphoma (THL) was ascertained. Control specimens consisted of cervical lymph nodes obtained from patients with negative diagnosis for neoplastic diseases.

Immunohistochemical evaluation. Immunohistochemistry was performed on $4-\mu \mathrm{m}$ tissue sections previously plated on silane-coated glass slides (Electron Microscopy Sciences, Hatfield, USA). In brief, paraffin tissue sections were treated with xylene and re-hydrated. For the detection of ECM components, slides were subjected for $30 \mathrm{~min}$ with $3 \mu \mathrm{l} / \mathrm{ml}$ hydrogen peroxide in methanol to quench endogenous peroxidase activity and then incubated with appropriately diluted antibodies to laminin or fibronectin. Sections were then incubated to the peroxidase-coupled second antibody $\mathrm{LSAB}^{+}$system for $30 \mathrm{~min}$ at room temperature. We developed the chromogen with immersion of the slides in a diaminobenzidine- $\mathrm{H}_{2} \mathrm{O}_{2}$ substrate for $5 \mathrm{~min}$. The slides were counterstained with haematoxylin, dehydrated and mounted under cover slides.

Statistical analysis. Statistical significance was determined by One-way ANOVA, followed by Newman-Keuls multiple comparison test. Values of $\mathrm{p}<0.05$ were considered significant. Data were expressed as mean \pm standard error.

\section{Results}

Expression of $\beta_{1}$-integrin receptors on U-937 cells and adhesion to corresponding ECM ligands. U937 cell interactions with proteins of the ECM are mediated, although not exclusively, by different receptors of the $\beta_{1}$ integrin family (25). We therefore investigated U937 cells for $\beta_{1}$ integrin expression using cytofluorometry. As seen in Fig. 2, CD29 (the $\beta_{1}$ integrin chain) was largely expressed. Accordingly, cells were positive for both fibronectin receptors, although expression of VLA-5 ( $\alpha 5 \beta 1$, detected with the anti-CD49e antibody) was clearly higher than that seen for VLA-4 $(\alpha 4 \beta 1$, revealed with the anti-CD49d reagent). These results reveal that the VLA-5 fibronectin receptor is preferentially expressed when compared to VLA-4. The data presented were obtained until the 3 rd day of culture, since we noticed that the membrane expression of these integrins decreased after further culturing in serum containing-medium (data not shown).

In order to test cell adhesion abilities to ECM-coated plates, U-937 cells in the third culture passage were used. We observed that in FN-coated plates the adhesion was increased in about 13 to 16 times when compared to adhesion to BSA (Fig. 3A). Moreover, we observed various cells on the FN-coated plactes, which were spread, exhibiting cytoplasmic processes (Fig. 3B). The adhesion of cells to laminin-coated plates was not different to the control assays. Colorimetric assay of attached cells had similar results (data not shown).

Pre-incubation of U-937 cells with synthetic peptides inhibited attachment of the cells to FN-coated substrates. More than $70 \%$ of U937 cells were unattached in the presence of

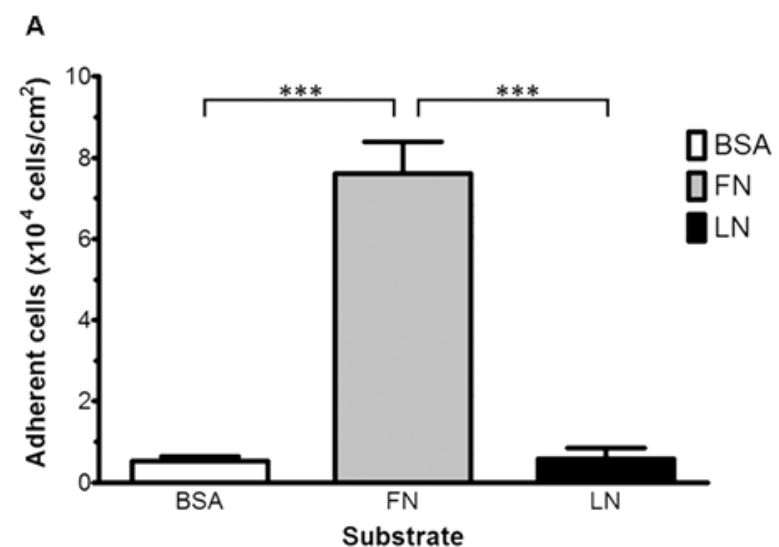

B

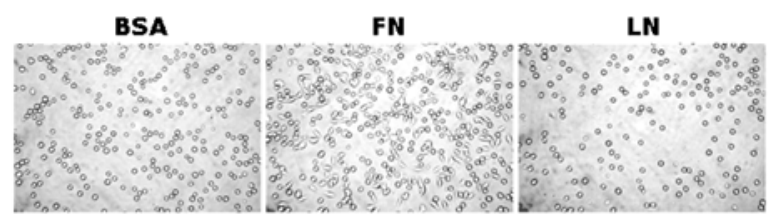

Figure 3. Specific adhesion of true histiocytic lymphoma U-937 to ECM fibronectin. Cells were incubated on bovine serum albumin (BSA), fibronectin (FN) or laminin-coated (LN) plates, as described in Materials and methods. A, Numbers of adherent viable cells, as assessed by trypan blue exclusion. B, Representative microscopic fields in the same three conditions. Note that in the fibronectin-coated plate, many cells acquired a spindle-shaped profile. Data are shown as means \pm SE of three independent experiments performed in triplicate. ${ }^{* * *} \mathrm{p}<0.001$. Original magnification $\mathrm{x} 200$

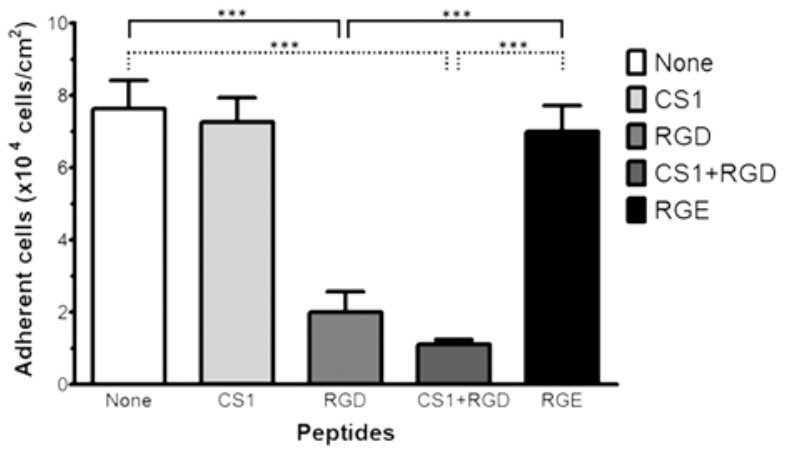

Figure 4. Inhibition of true histiocytic lymphoma U-937 cell adhesion to FN-coated surfaces by the VLA-5 inhibiting RGD peptide. Cells were preincubated in the presence of soluble peptides (RGD, CS-1, RGD plus CS-1 or RGE; $500 \mu \mathrm{g} / \mathrm{ml}$ ) before adhesion to fibronectin. Numbers of adherent viable cells were assessed by trypan blue exclusion. Data are shown as means $\pm \mathrm{SE}$ of three independent experiments performed in triplicate. ${ }^{* * *} \mathrm{p}<0.001$.

$500 \mu \mathrm{g} / \mathrm{ml}$ RGD peptide. The mixture of RGD and CS-1 peptides showed a similar inhibitory effect compared with those by RGD peptide alone. Importantly, the CS-1 and the control peptide, RGE, did not block cell adhesion (Fig. 4). These findings clearly point to the notion that the response of U-937 cells to fibronectin is mediated by VLA- 5 rather than VLA-4.

In accordance to the cytofluorometric data, cells derived from long-term cultures (that reduce FN receptor expression) highly decreased the adherence to fibronectin (not shown).

Migration arrest of U-937 cells onto FN substrates. The ability of a cancer cell to migrate is governed by several 


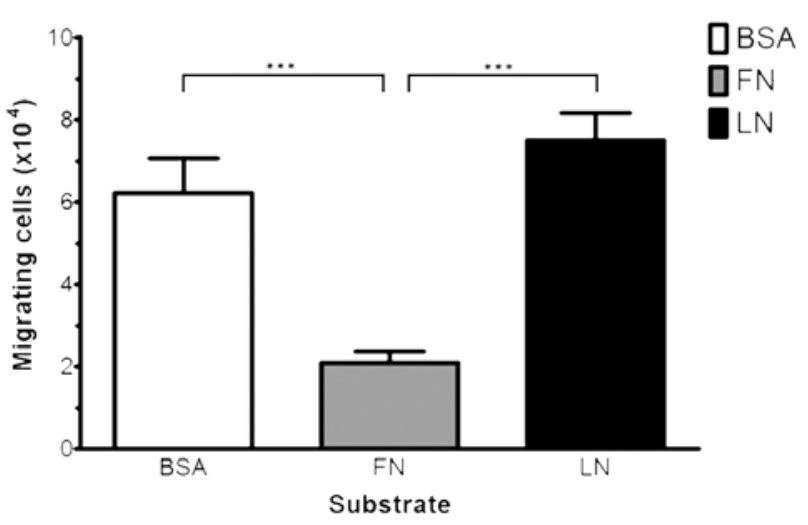

Figure 5. Fibronectin arrests migration of true histiocytic lymphoma U-937 cells. Data represents the total numbers of migrating cells in transwell chambers after stimulation with bovine serum albumin (BSA), fibronectin (FN) or laminin (LN). Migration assay was performed as described in Materials and methods. Numbers of migrating viable cells were assessed by trypan blue exclusion. The data are shown as means $\pm \mathrm{SE}$ of four independent experiments performed in triplicate. ${ }^{* * *} \mathrm{p}<0.001$.

factors, and depends on the dynamic interaction with the ECM (26). Using the transwell migration assay, we compared the effects of ECM proteins on U-937 cell migration. In BSAcoated control inserts, $\sim 10 \%$ of the U-937 cells spontaneously migrated after $4 \mathrm{~h}$. When cells were challenged to migrate onto FN-coated inserts, a significant decrease of migration was observed. This was not observed in laminin-coated inserts, where values for cell migration were not different from those seen in the BSA-coated inserts (Fig. 5).

U-937 cell proliferation and survival on FN substrates. We monitored U-937 cell proliferation, on ECM-coated plates. Cells initially adhered to FN-coated wells, but no differences in the proliferation rate were observed when cells were cultured onto FN or BSA substrates (Fig. 6).

In early studies it was shown that death of U-937 cells could be induced by serum withdrawal (27). To determine if cell-matrix attachment modulates cell survival under serumdeprivation conditions, cells were plated on 24-well plates coated with fibronectin or BSA and cultured for 24, 48 and $72 \mathrm{~h}$. We found that FN substrate did not alter U-937 cell survival under serum-deprivation conditions when compared to BSA substrate (Fig. 7).

Increase in fibronectin contents within lymph node of THL patient. Based on in vitro results showing ECM effects on the behavior of a THL cell line, we searched for the ECM deposition in vivo studying a case of THL. We analyzed the sub-capsular region from normal or THL infiltrated lymph nodes. In the THL specimens we found large cells with a more open nuclear chromatin pattern, with one or more prominent centrally-located nucleolus (Fig. 1). When we analyzed ECM protein staining, we observed in normal lymph nodes, a larger FN deposition in the capsule with a rather weak expression in the cortical region. In THLinfiltrated node a strong FN labeling was observed in the capsule as well as in the cortical region. This was paralleled by reticular fiber deposition around cortical cells, possibly coordinated by malignant infiltration (Fig. 8). Differently,

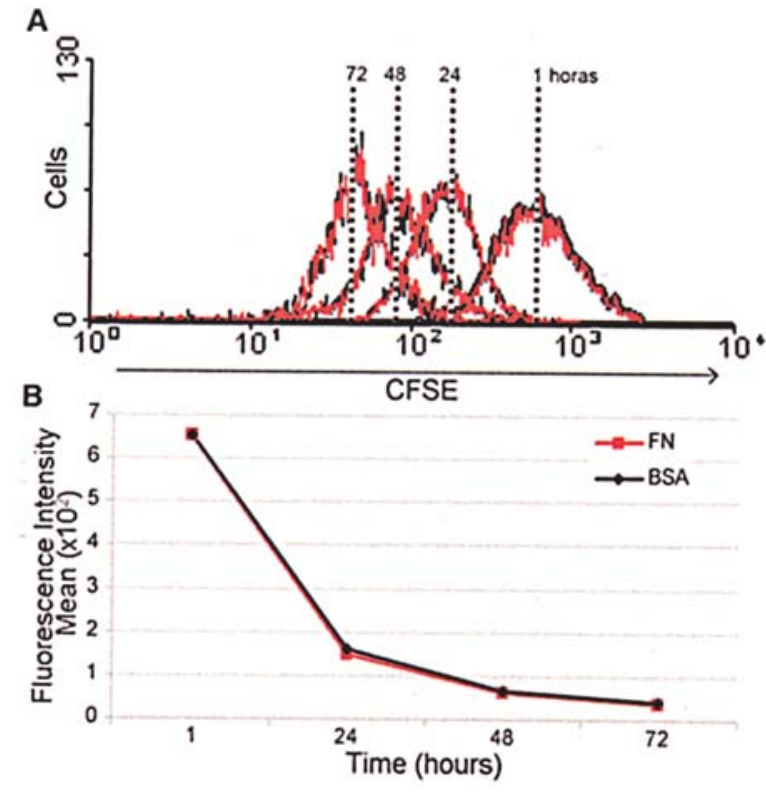

Figure 6. Fibronectin does not alter true histiocytic lymphoma U-937 cell proliferation. Cell proliferation was visualized by loss of CFSE after 1, 24, 48 and $72 \mathrm{~h}$ of culture on BSA (black line) or FN-coated (red line) wells. A, Representative histograms showing the proliferation profiles. B, The X-Y plot graphs represent the mean of CFSE fluorescence intensity on U-937 cells in three independent experiments performed in duplicate.

laminin immunostaining revealed a uniform distribution in capsule and cortex in both control and THL-infiltrated lymph nodes (data not shown).

\section{Discussion}

Herein, we demonstrated the role of fibronectin substrate on U-937 histiocytic lymphoma cell line adhesion and migration. We showed that the interaction with fibronectin can strongly adhere and arrest migration of U-937 cells. These responses seems to be mediated specifically by CD49e/CD29 ( $\alpha 5$ B1 integrin, VLA-5) rather than CD49d/ CD29 ( $\alpha 431$ integrin, VLA-5), since it can be abrogated by the VLA-5 blocking peptide RGD, but not by the CS-1 sequence, which is specifically recognized by VLA-4. This difference is in keeping with the higher membrane expression of CD49e, when compared to CD49d. This correlates to normal tumor progression in which cancer cells invade, attach, remodel the ECM microenvironment and establish on host tissues (5).

It should be noted however, that although U-937 cells do respond to fibronectin, this ECM component does not seem to be relevant for proliferation or death rescue of these cells in conditions of serum deprivation.

For hematological malignancies, the role of fibronectin can differ: while in some tumors fibronectin induces neoplastic survival and/or development $(28,29)$, in others, its role for malignant progression is not relevant (30). In the case of THL cells, fibronectin does not alter cell growth but appears to modulate cell attachment and migration. This is in keeping with other findings showing that the presence of soluble factors together with fibronectin may regulate cell attachment as well as increase cell migration, that may favor THL malignant infiltration in lymph nodes and in other tissues (31). 
A

$\mathrm{Pl}$
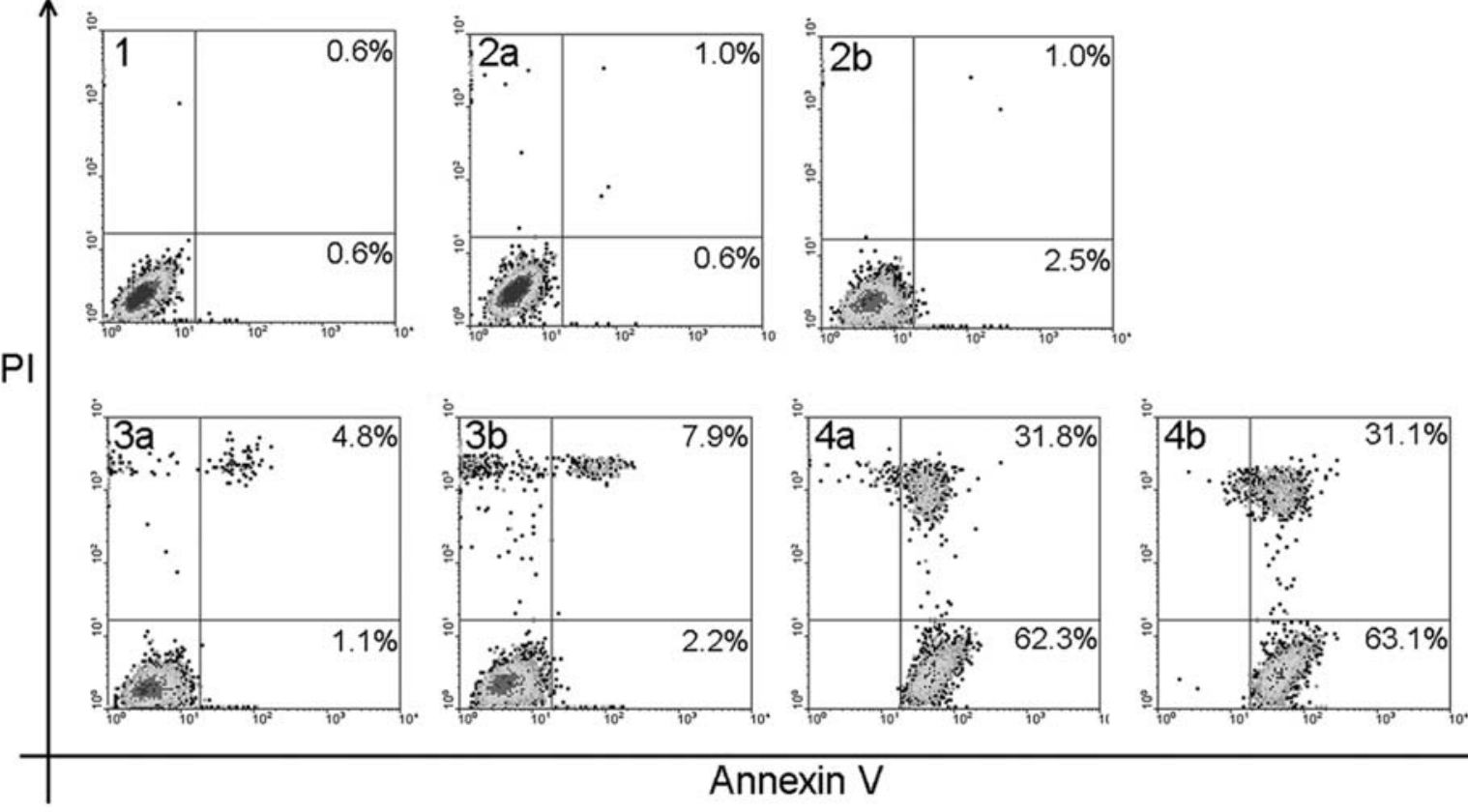

B

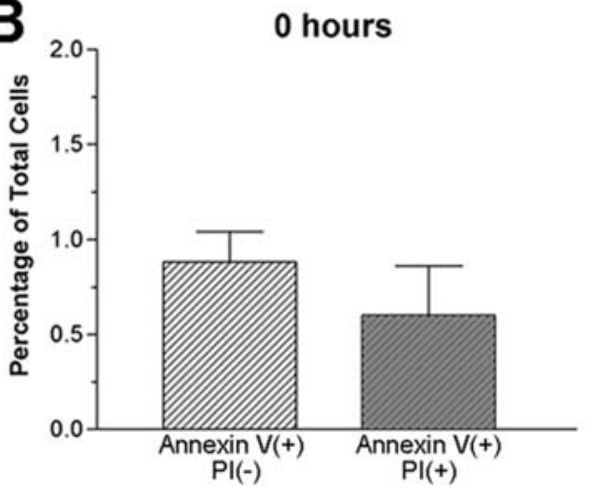

48 hours

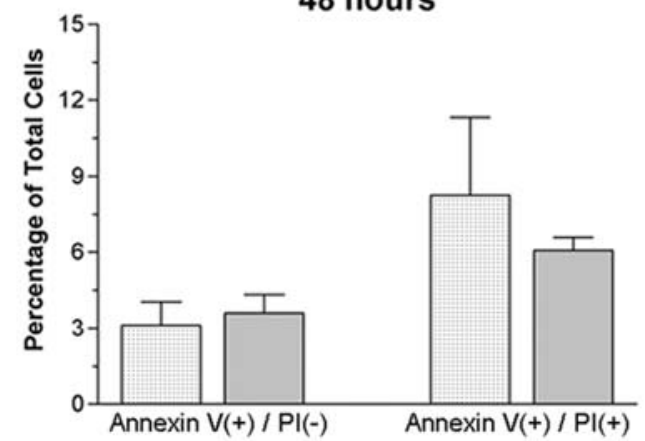

Annexin V
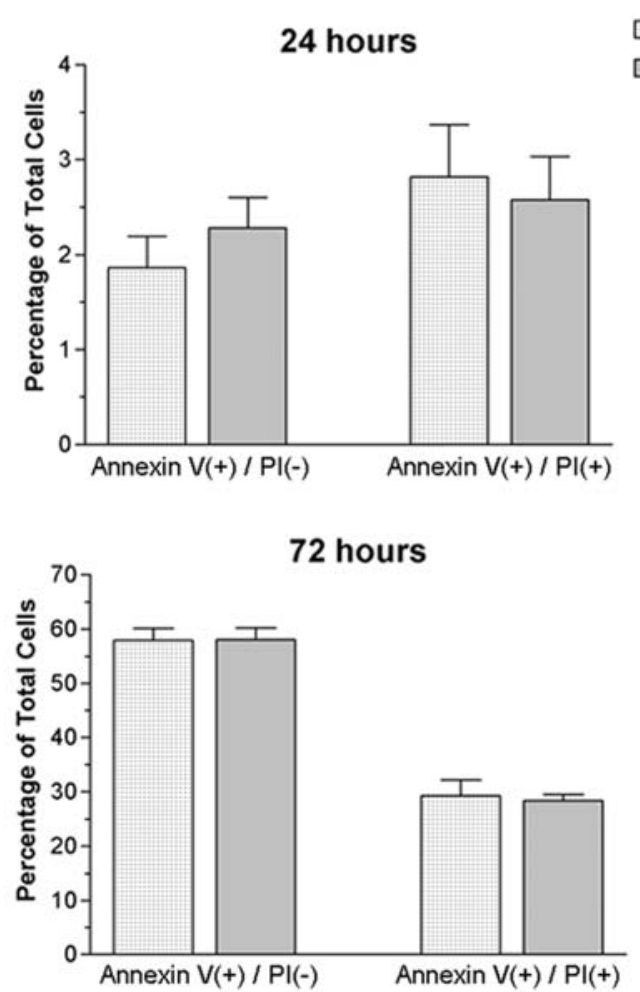

Figure 7. Fibronectin does not alter true histiocytic lymphoma U-937 cell survival under serum-deprivation. (A) Representative histograms showing propidium iodide (PI) and annexin V staining at the point zero (1) of culture, $24 \mathrm{~h}$ of culture on BSA ( $2 \mathrm{a})$ or FN (2b), $48 \mathrm{~h}$ of culture on BSA ( $3 \mathrm{a})$ or FN ( $3 \mathrm{~b}$ ), and $72 \mathrm{~h}$ on BSA (4a) or FN-coated (4b) wells. (B) Percentages of annexin-V positive/PI negative (early apoptosis) and annexin-V positive/PI positive (late apoptosis or necrosis) cells cultured on BSA or FN-coated wells for $0,24,48$ and $72 \mathrm{~h}$ under serum-deprivation. Data are shown as means \pm SE of three independent experiments performed in triplicate.

A second aspect deserving discussion refers to which fibronectin receptor(s) would be involved in FN-driven THL cell responses. In this respect, it has been shown that fibroblast adhesion to LDV sequence of fibronectin via $\alpha 4 \beta 1$ integrin represses $\alpha 5 \beta 1$-mediated interstitial collagenase expression (32). Additionally, fragmentation of fibronectin by plasmin de-repress $\alpha 5 \beta 1$-mediated invasion during wound healing, indicating an important attribute of $\alpha 4 \beta 1$ integrin in regulation $\alpha 5 \beta 1$-induced invasion $(33,34)$. In our studies, it was clear that changes in adhesiveness and migration of U-937 cells after exposure to fibronectin occurred through the VLA-5 receptor, rather than VLA-4.

In connection with the in vitro data, we also observed that lymph nodes infiltrated by THL cells had a greater 


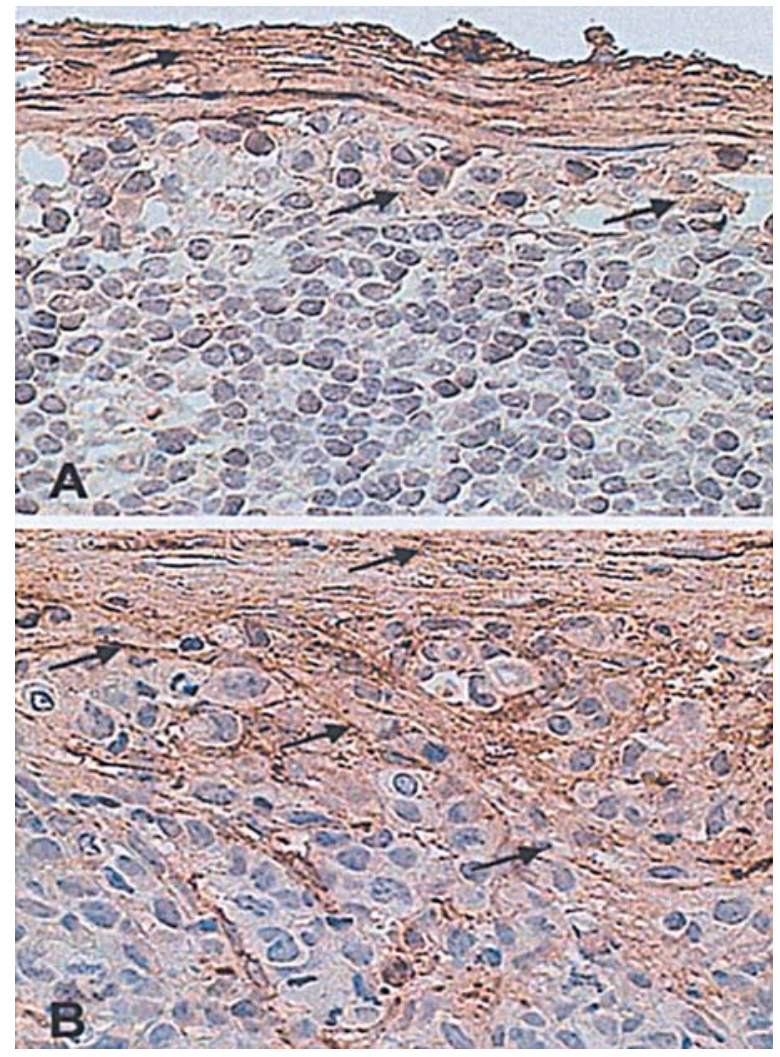

Figure 8. Immunostaining of fibronectin in normal (A) or THL-infiltrated (B) cervical lymph nodes. Arrows indicate the deposition of the ECM protein. Note that fibronectin staining is much denser in THL than control lymph node, with clearcut FN-containing fibrils (arrows). Specimens were counterstained with haematoxylin. Original magnification $\times 400$.

deposition of fibronectin (but not laminin) around malignant cells. The over-expression of fibronectin in THL infiltrated lymph node specimens, together with the behavior observed for U-937 cells on FN leads to the hypothesis that the establishment of micrometastasis seen in THL patients may be related to FN-driven migration and adhesion of the malignant cells.

\section{Acknowledgements}

This work was supported by grants from the Oswaldo Cruz Foundation (Fiocruz), Coordenação de Aperfeiçoamento de Pessoal de Nível Superior (CAPES, Brazilian Ministry of Education), Conselho Nacional de Desenvolvimento Científico e Tecnológico (CNPq) and Fundação de Ciência e Tecnologia, Santa Catarina (FUNCITEC/SC).

\section{References}

1. Vacca A, Ria R, Presta M, Ribatti D, Iurlaro M, Merchionne F, Tanghetti L and Dammacco F: $\alpha \mathrm{v} 33$ integrin engagement modulates cell adhesion, proliferation, and protease secretion in human lymphoid tumor cells. Exp Hematol 29: 993-1003, 2001.

2. Karmakar S and Mukherjee R: Integrin receptors and ECM proteins involved in preferential adhesion of colon carcinoma cells to lung cells. Cancer Lett 196: 217-227, 2003.

3. Woodhouse EC, Chuaqui RF and Liotta LA: General mechanisms of metastasis. Cancer 80: 1529-1537, 1997.

4. Juliano RL: Signal transduction by cell adhesion receptors and the cytoskeleton: functions of integrins, cadherins, selectins, and immunoglobulin-superfamily members. Annu Rev Pharmacol Toxicol 42: 283-323, 2002.
5. Hood JD and Cheresh DA: Role of integrins in cell invasion and migration. Nat Rev 2: 91-100, 2002.

6. Hynes RO: Integrins: bidirectional, allosteric signaling machines. Cell 110: 673-687, 2002.

7. Wahl SM, Feldman GM and McCarthy JB: Regulation of leukocyte adhesion and signaling in inflammation and disease. J Leukoc Biol 59: 789-796, 1996.

8. Ulbrich H, Eriksson EE and Lindbom L: Leukocyte and endothelial cell adhesion molecules as targets for therapeutic interventions in inflammatory disease. Trends Pharmacol Sci 24: 640-647, 2003.

9. Wayner EA, Garcia-Prado A, Humphries M, McDonald JA and Carter WG: Identification and characterization of the T lymphocyte adhesion receptor for an alternative cell attachment domain (CS-1) in plasma fibronectin. J Cell Biol 109: 1321-1330, 1989.

10. Pierschbacher MD and Ruoslahti E: Cell attachment activity of fibronectin can be duplicated by small synthetic fragments of the molecule. Nature 309: 30-33, 1984.

11. Chigaev A, Zwartz G, Graves SW, Dwyer DC, Tsuji H, Foutz TD, Edwards BS, Prossnitz ER, Larson RS and Sklar LA: $\alpha 4 \beta 1$ integrin affinity changes govern cell adhesion. J Biol Chem 278: 38174-38182, 2003

12. Sadovnikova E, Parovichnikova EN, Semikina EL, Kopiltsova EA, Svinareva DA, Belkin VM, Torubarova NA and Savchenko VG: Adhesion capacity and integrin expression by dendritic-like cells generated from acute myeloid leukemia blasts by calcium ionophore treatment. Exp Hematol 32: 563-570, 2004.

13. Elghetany MT: True histiocytic lymphoma: Is it an entity? Leukemia 11: 762-764, 1997

14. Harris NL, Jaffe ES, Diebold J, Flandrin G, Muller-Hermelink HK, Vardiman J, Lister TA and Bloomfield CD: World Health Organization classification of neoplastic diseases of the hematopoietic and lymphoid tissues: report of the Clinical Advisory Committee Meeting, Airlie House, Virginia, November 1997. J Clin Oncol 17: 3835-3849, 1999.

15. Bouabdallah R, Abena P, Chetaille B, Aurran-Schleinitz T, Sainty D, Dubus P, Arnoulet C, Coso D, Xerri L and Gastaut JA: True histiocytic lymphoma following B-acute lymphoblastic leukaemia: case report with evidence for a common clonal origin in both neoplasms. Br J Haematol 113: 1047-1050, 2001.

16. Chain M, Dei-Cas I, Carbia S, Xifra M, Wright D, Glorio R, Deves A and Woscoff A: Cutaneous true histiocytic malignancy: True histiocytic lymphoma. J Am Acad Dermatol 50: S9-S10, 2004.

17. Soria C, Orradre JL, Garcia-Almagro D, Martinez B, Algara P and Piris MA: True histiocytic lymphoma (monocytic sarcoma). Am J Dermatopathol 14: 511-517, 1992.

18. Hennessy BT, Hanrahan EO and Daly PA: Non-Hodgkin lymphoma: an update. Lancet Oncol 5: 341-353, 2004.

19. Sundstrom $\mathrm{C}$ and Nilsson K: Establishment and characterization of human histiocytic lymphoma cell line (U-937). Int J Cancer 17: 565-577, 1976.

20. Dalmau SR, Freitas CS and Savino W: Upregulated expression of fibronectin receptors underlines the adhesive capability of thymocytes to thymic epithelial cells during the early stages of differentiation: lessons from sublethally irradiated mice. Blood 93: 974-990, 1999.

21. Segat D, Pucillo C, Marotta G, Perris R and Colombatti A: Differential attachment of human neoplastic B cells to purified extracellular matrix molecules. Blood 83: 1586-1594, 1994.

22. Lyons $\mathrm{AB}$ and Parish CR: Determination of lymphocyte division by flow cytometry. J Immunol Methods 171: 131-137, 1994.

23. Cotta-de-Almeida V, Villa-Verde DM, Lepault F, Pleau JM, Dardenne M and Savino W: Impaired migration of NOD mouse thymocytes: a fibronectin receptor-related defect. Eur J Immunol 34: 1578-1587, 2004.

24. Vermes I, Haanen C, Steffens-Nakken H and Reutelingspeyer C: A novel assay for apoptosis: flow cytometric detection of phosphatidylserine expression on early apoptotic cells using fluorescein labelled annexin V. J Immunol Methods 184: 39-51, 1995.

25. Pucillo CEM, Colombatti A, Vitale M, Salzano S, Rossi G and Formisano S: Interactions of promonocytic U937 cells with proteins of the extracellular matrix. Immunology 80: 248-252, 1993.

26. Ioachim E, Charchanti A, Briasoulis E, Karavasilis V, Tsanou H, Arvanitis DL, Agnantis NJ and Pavlidis N: Immunohistochemical expression of extracellular matrix components tenascin, fibronectin, collagen type IV and laminin in breast cancer: their prognostic value and role in tumour invasion and progression. Eur J Cancer 38: 2362-2370, 2002. 
27. Kim DK, Cho ES, Seong JK and Um HD: Adaptive concentrations of hydrogen peroxide suppress cell death by blocking the activation of SAPK/JNK pathway. J Cell Sci 114: 4329- 4334, 2001.

28. Peled A, Hardan I, Trakhtenbrot L, Gur E, Magid M, DarashYahana M, Cohen N, Grabovsky V, Franitza S, Kollet O, Lider O, Alon R, Rechavi G and Lapidot T: Immature leukemic CD $34{ }^{+} \mathrm{CXCR} 4{ }^{+}$cells from CML patients have lower integrindependent migration and adhesion in response to the chemokine SDF-1. Stem Cells 20: 259-266, 2002.

29. Molla A and Block MR: Adherence of human erythroleukemia cells inhibits proliferation without inducing differentiation. Cell Growth Differ 11: 83-90, 2000.

30. Bhatia R, Williams AD and Munthe HA: Contact with fibronectin enhances preservation of normal but not chronic myelogenous leukemia primitive hematopoietic progenitors. Exp Hematol 30: 324-332, 2002.
31. Weston CA and Weeks BS: bFGF stimulates U937 cell adhesion to fibronectin and secretion of gelatinase B. Biochem Biophys Res Commun 228: 318-323, 1996.

32. Huhtala P, Humphries MJ, McCarthy JB, et al: Cooperative signaling by alpha 5 beta 1 and alpha 4 beta 1 integrins regulates metalloproteinase gene expression in fibroblasts adhering to fibronectin. J Cell Biol 129: 867-879, 1995.

33. Grinnell $\mathrm{F}$ and Zhu M: Identification of neutrophil elastase as the proteinase in burn wound fluid responsible for degradation of fibronectin. J Invest Dermatol 103: 155-161, 1994.

34. Greiling D and Clark RA: Fibronectin provides a conduit for fibroblast transmigration from collagenous stroma into fibrin clot provisional matrix. J Cell Sci 110: 861-870, 1997 